(2) Open Access Full Text Article

CASE REPORT

\title{
Asymmetric severity of diabetic retinopathy in Waardenburg syndrome
}

This article was published in the following Dove Press journal:

Clinical Ophthalmology

6 December 2011

Number of times this article has been viewed

\section{Tomoyuki Kashima \\ Hideo Akiyama \\ Shoji Kishi}

Department of Ophthalmology, Gunma University School of Medicine, Gunma 37I-85II, Japan
Correspondence: Tomoyuki Kashima Department of Ophthalmology, Gunma University School of Medicine, 3-39-I5 Showamachi, Maebashi, Gunma 37I-85II, Japan

Tel +8I 272208338

Fax +8I 53220384 I

Email kasimatomoyuki@yahoo.co.jp
Abstract: A 30-year-old female patient was referred to our institution due to vitreous hemorrhage. Best corrected visual acuity of her right and left eyes at her initial visit was 10/20 and 20/20, respectively. Although hypochromic iris was observed in the superior iris between the 10 and 2 o'clock positions in her right eye, her entire left eye exhibited hypochromic iris. Hypopigmentation of the fundus was seen in the superior part of her right eye. This eye also had a huge neovascularization on the optic disc that was 7 discs in diameter. Conversely, her left fundi showed hypopigmentation of the fundus in the entire region of the left eye, and dot hemorrhages were observed all over the left fundi, although no neovascularization could be seen microscopically. Fluorescein angiography showed a huge neovascularization in the right eye and a tiny neovascularization in the left eye. Gene analysis revealed the presence of the $P A X 3$ gene homeobox domain mutation, which led to her being diagnosed as Waardenburg syndrome type 1. Magnetic resonance angiography showed there was no obstructive region at either of the internal carotid arteries and ophthalmic arteries. The severity of the diabetic retinopathy appeared to be correlated with the degree of hypopigmentation in the posterior fundus. We speculate that hypopigmentation of the fundus in Waardenburg syndrome may be responsible for the reduction in retinal metabolism, which led to a reduction in oxygen consumption and prevented further aggravation of the diabetic retinopathy. Only laser treatments using short wavelengths was effective in this case. While the extinction coefficient for hemoglobin when using green light is higher than when using yellow light, the differences between these wavelengths tend to disappear when oxygenated hemoglobin is present. To the best of the authors' knowledge, this is the first case report of a patient with Waardenburg syndrome and diabetic retinopathy.

Keywords: asymmetry, diabetic retinopathy, Waardenburg syndrome, albinism, hypopigmentation

\section{Introduction}

Waardenburg syndrome, which was first reported in 1951 by Waardenburg, is a typical auditory pigmentary syndrome that is accompanied by a lateral displacement of the lacrimal puncta, patchy abnormal pigmentation of the eyes, hair and skin, and sensorineural hearing loss. ${ }^{1}$ In such cases, if an iris shows a sector that is hypochromic, then the corresponding sector of the fundus should also be hypochromic. ${ }^{2}$ The etiology is assumed to be a disorder of differentiation and involves movement of the neural crest. ${ }^{3}$ On the other hand, diabetic retinopathy induced by microvascular occlusion causes proliferative changes and results in visual disturbance. Panretinal photocoagulation is one of the major treatments used in patients with diabetic retinopathy. The efficacy of this treatment is related to its reduction of retinal oxygen requirements, combined with increased retinal oxygen saturation. 
In addition, to the best of our knowledge, there have been no reports on cases of diabetic retinopathy with fundus hypopigmentation, similar to the symptoms seen in Waardenburg syndrome. Here, we report a case of Waardenburg syndrome with diabetic retinopathy, the severity of which was far different in eyes with different pigmentation.

\section{Case report}

A 30-year-old female patient first discovered glycosuria 3 years prior to being examined at a medical institution for the condition. The patient initially sought medical treatment for a floating spot in her right eye, and after it was determined that this was due to vitreous hemorrhage, she was referred to our institution. Best corrected visual acuity of her right and left eyes at her initial visit was 10/20 and 20/20, respectively. Similar to her father and grandfather, the patient had white hair. She had dystopia canthorum identified by calculation of the $\mathrm{W}$ index (2.01), but did not have sensorineural hearing loss. Although hypochromic iris was observed in the superior iris between the 10 and 2 o'clock positions in her right eye, her entire left eye exhibited hypochromic iris (Figure 1).
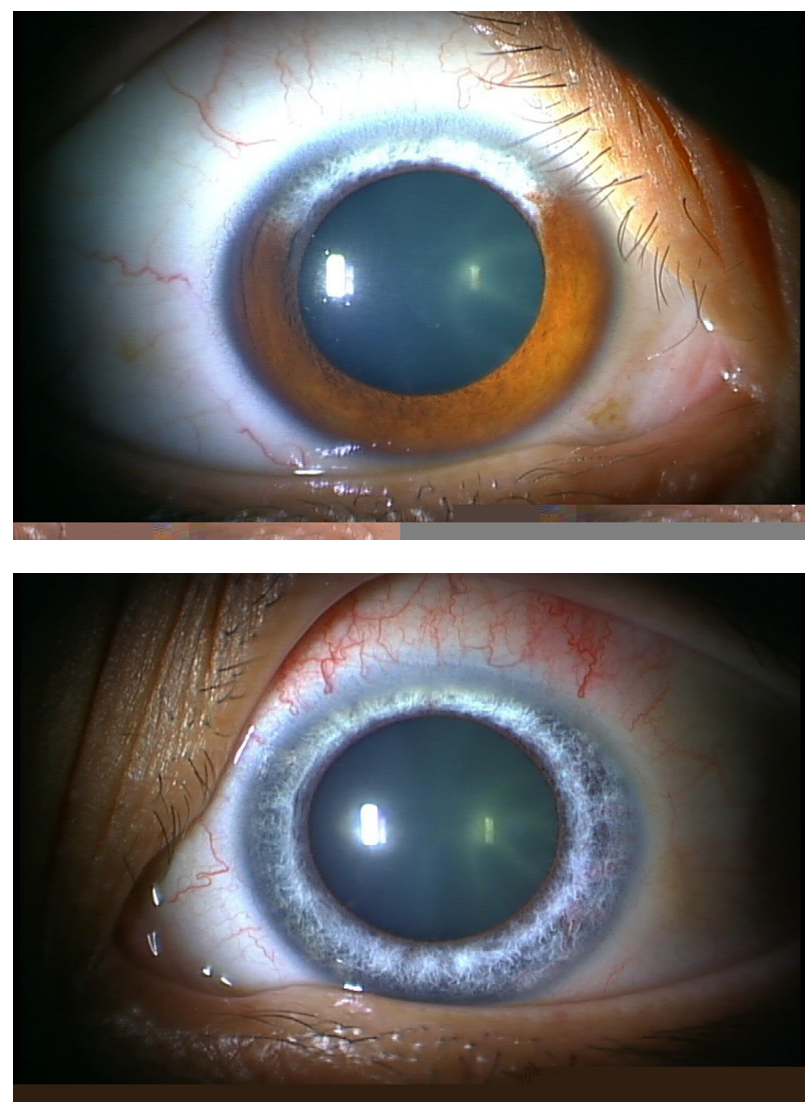

Figure I Photograph of the anterior segment. Heterochromia iridis is observed in the superior iris between the 10 and 2 o'clock positions in the right eye (Top). Heterochromia iridis of the entire iris of the left eye (Bottom). The patient also had mild anterior and posterior subcapsular cataract in both eyes.
Mild anterior and posterior subcapsular cataract was found in both eyes, and hypopigmentation of the fundus was seen in the superior part of her right eye. This eye also had a huge neovascularization on the optic disc that was 7 discs in diameter and was surrounded by preretinal hemorrhage. Conversely, her left fundi showed hypopigmentation of the fundus in the entire region of the left eye, and dot hemorrhages were observed all over the left fundi. However, no neovascularization could be seen microscopically (Figure 2). Optical coherence tomography seemed to demonstrate slight outer retinal atrophy in the left eye (Figure 3). Fluorescein angiography showed a huge neovascularization on the optic disc in the right eye. Only a tiny neovascularization was noted on the left eye (Figure 4). Gene analysis revealed the presence of a $P A X 3$ gene homeobox domain mutation which was detailed as mutation in exon 6: F267I (801T changed to A), ${ }^{4}$
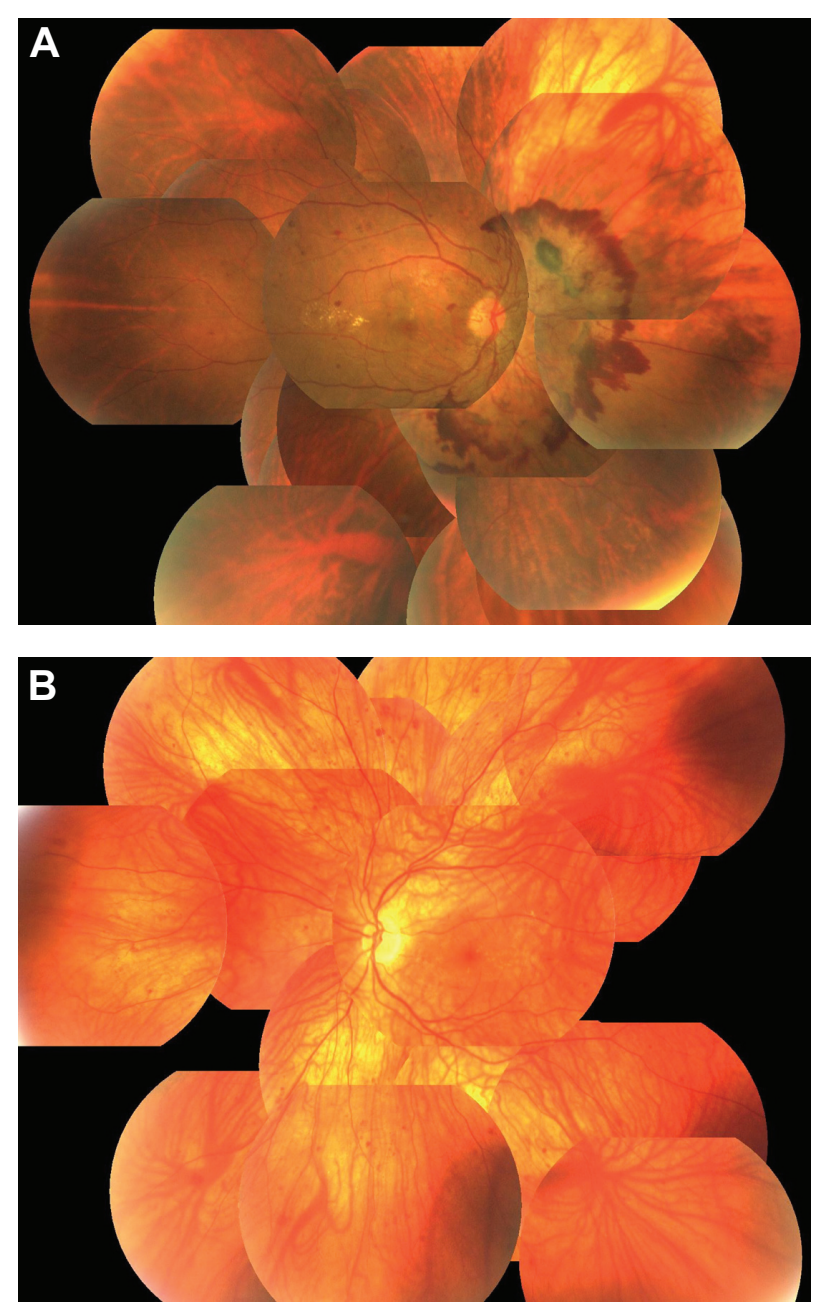

Figure 2 Panoramic fundus photograph. (A) Huge neovascularization can be seen on the optic disc in the right eye. Hypopigmentation of the retinal area exists at upper peripheral region. (B) The entire retina is hypopigmented in the left eye. Major choroidal vessels can be seen throughout the retina. Neovascularization is not apparent in this eye. 


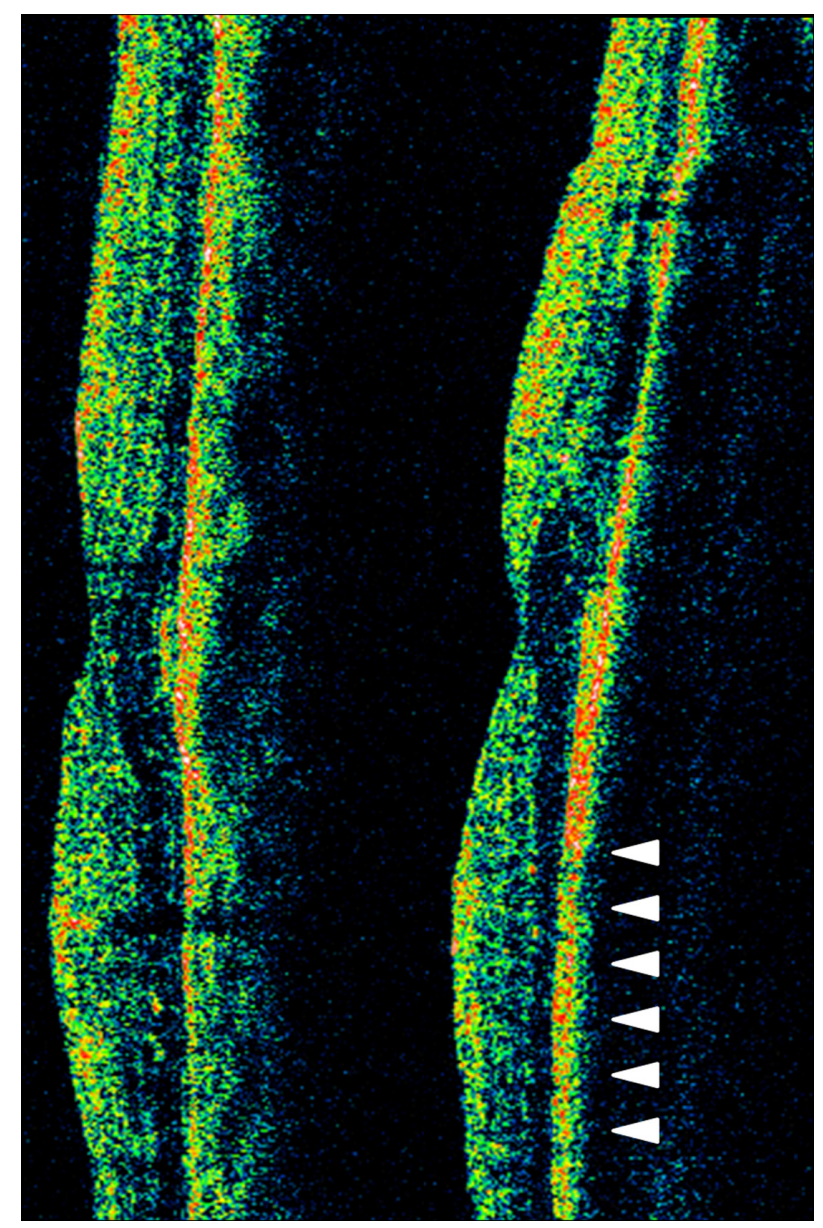

Figure 3 Optical coherence tomography of both eyes with vertical scan (left). Optical coherence tomography image shows normal foveal structure in the right eye (right). The inferior part of outer retinal layer seems to be thin in inferior area of the left eye (arrowhead).

and led to her being diagnosed as Waardenburg syndrome type $1 .{ }^{5}$ Magnetic resonance imaging and magnetic resonance angiography showed that there was no obstructive region at either of the internal carotid arteries or ophthalmic arteries. ${ }^{6}$ We performed panretinal photocoagulation in both eyes using a multicolor photocoagulation laser system (Novus Varia ${ }^{\circledR}$, Lumenis Ltd, Yokneam, Israel). Since the yellow light laser (wavelength $561 \mathrm{~nm}$ ) was invalid for the hypopigmented areas of the fundus, we chose to use the green light laser (wavelength $532 \mathrm{~nm}$ ) in order to perform panretinal photocoagulation over the entire extramacular area. Due to the diabetic retinopathy, tractional foveal detachment in her right eye and mild vitreous hemorrhage of her left eye occurred at 10 months after panretinal photocoagulation. Because of this, we then carried out pars plana vitrectomy in both eyes. At approximately 2 years after her surgery, her condition normalized, and at the present time, her best corrected visual acuity remains at 20/30 and 20/20 in her right left eyes, respectively.
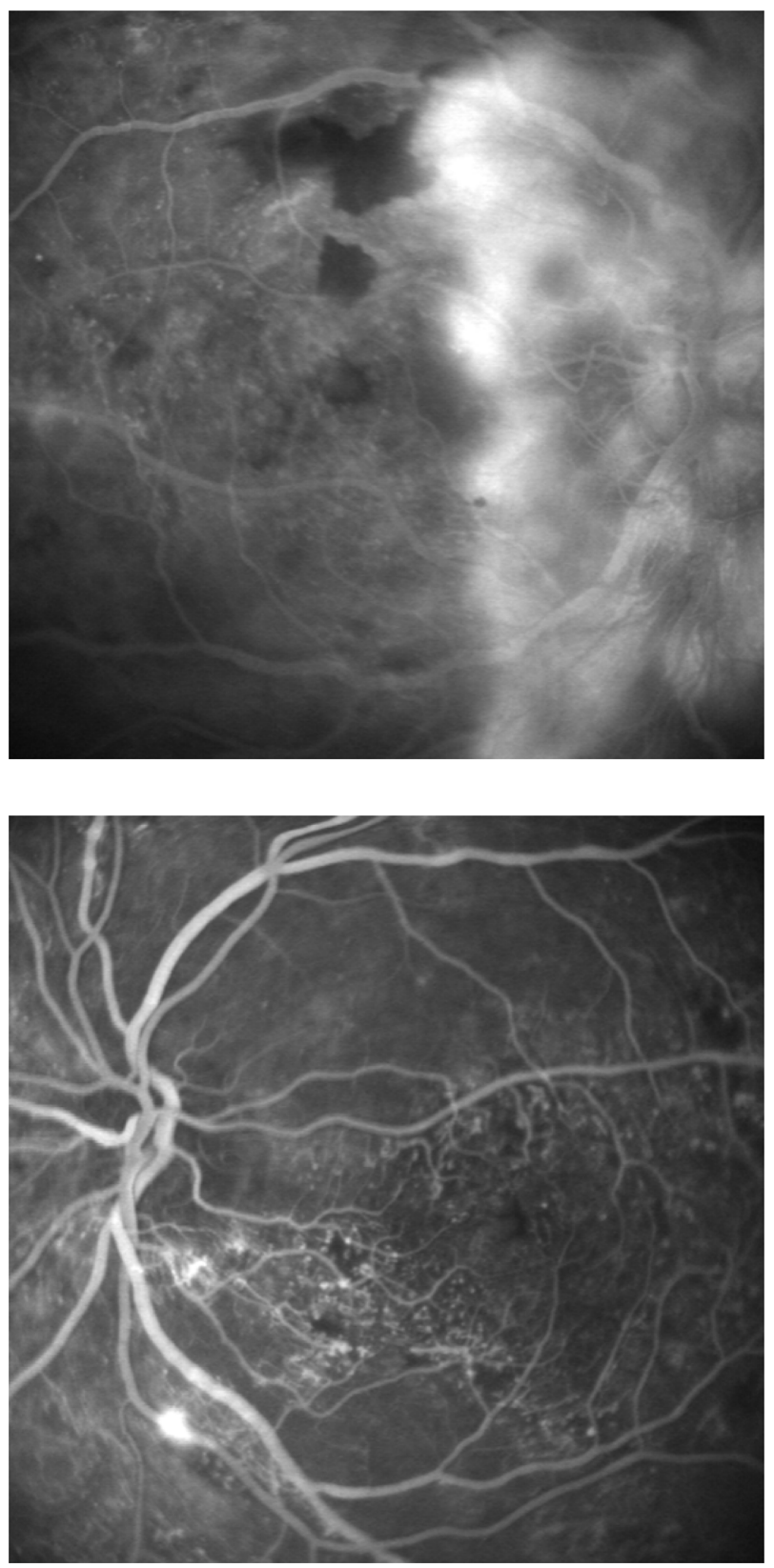

Figure 4 Fundus photograph of fluorescein angiography. Massive dye leakage from the disc neovascularization can be seen in the right eye. The neovascularization is surrounded by preretinal hemorrhage (Top). No obvious dye leakage, except for a slight leakage of the inferior artery, is seen in the left eye. A vascular bed occlusion is apparent inside of the arcade vessels (Bottom).

\section{Discussion}

The severity of diabetic retinopathy appeared to be correlated with the degree of hypopigmentation in the posterior fundus in this patient. However, magnetic resonance angiography did not show any internal carotid obstruction, and thus there was no obvious explanation for the asymmetric diabetic retinopathy. Previous studies have postulated that patients with diabetes and retinopathy do not develop proliferative diabetic retinopathy since a reduction in the retinal metabolism 
would be associated with a decrease in the development of diabetic retinopathy. ${ }^{7-9}$ Based on this, we speculate that hypopigmentation of the fundus in Waardenburg syndrome may be responsible for reduction in retinal metabolism, which led to a reduction in oxygen consumption, and perhaps prevented further aggravation of diabetic retinopathy.

In the present case, only laser treatments using short wavelengths proved to be effective. When using laser photocoagulation in the fundus, light is mainly absorbed by melanin, xanthophylls, and hemoglobin. Obana a reported that when performing photocoagulation of the fundus, melanin was the main substance of laser absorption. However, in patients with melanin deficiencies, differences in the hemoglobin absorption rate are of more importance. ${ }^{10}$ While hemoglobin's extinction coefficient when using green light is higher than when using yellow light, the differences between these wavelengths tend to disappear when oxygenated hemoglobin is present. ${ }^{11}$ We speculate that these extinction coefficient differences are the reason why the green light laser proved to be more effective for photocoagulation treatment of the hypopigmented fundus. To the best of the authors' knowledge, this is the first case report of a Waardenburg syndrome patient with diabetic retinopathy.

\section{Disclosure}

The authors report no conflicts of interest in this work.

\section{References}

1. Waardenburg PJ. A new syndrome combining developmental anomalies of the eyelids, eyebrows, and nose root with pigmentary of the iris and head hair and with congenital deafness. Am J Med Genet. 1951;3: 195-201.

2. Nork TM, Shihab ZM, Young RS, Price J. Pigment distribution in Waardenburg's syndrome: a new hypothesis. Graefes Arch Clin Exp Ophthalmol. 1986;224:487-492.

3. Read AP, Newton VE. Waardenburg syndrome. J Med Genet. 1997;34:656-665.

4. Nakamura M, Ishikawa O, Tokura Y. A novel missense mutation in the PAX3 gene in a case of Waardenburg syndrome type I. J Eur Acad Dermatol Venereol. 2009;23:708-709.

5. Tassabehji M, Read AP, Newton VE, et al. Waardenburg's syndrome patients have mutations in the human homologue of the Pax-3 paired box gene. Nature. 1992;355:635-636.

6. Mendrinos E, Machinis TG, Pournaras CJ. Ocular ischemic syndrome. Surv Ophthalmol. 2009;55:2-34.

7. de Gooyer TE, Stevenson KA, Humphries P, Simpson DA, Gardiner TA, Stitt AW. Retinopathy is reduced during experimental diabetes in a mouse model of outer retinal degeneration. Invest Ophthalmol Vis Sci. 2006; 47:5561-5568.

8. Arden GB. The absence of diabetic retinopathy in patients with retinitis pigmentosa: implications for pathophysiology and possible treatment. Br J Ophthalmol. 2001;85:366-370.

9. Dellaporta A. The negative coincidence of retinitis pigmentosa and proliferative diabetic retinopathy. Am J Ophthalmol. 1984;98:524.

10. Obana A, Miki T. The effect of melanin and hemoglobin on the dye laser photocoagulation in pigmented and albino rabbits. Nippon Ganka Gakkai Zasshi. 1989;93:844-851. Japanese.

11. Mainster MA. Wavelength selection in macular photocoagulation. Tissue optics, thermal effects, and laser systems. Ophthalmology. 1986;93:952-958.
Clinical Ophthalmology

\section{Publish your work in this journal}

Clinical Ophthalmology is an international, peer-reviewed journal covering all subspecialties within ophthalmology. Key topics include: Optometry; Visual science; Pharmacology and drug therapy in eye diseases; Basic Sciences; Primary and Secondary eye care; Patient Safety and Quality of Care Improvements. This journal is indexed on Submit your manuscript here: http://www.dovepress.com/clinical-ophthalmology-journal

\section{Dovepress}

PubMed Central and CAS, and is the official journal of The Society of Clinical Ophthalmology (SCO). The manuscript management system is completely online and includes a very quick and fair peer-review system, which is all easy to use. Visit http://www.dovepress.com/ testimonials.php to read real quotes from published authors. 